\title{
Expression of heat shock protein 70 and Annexin A1 in serum of patients with acutely severe traumatic brain injury
}

\author{
JUNJING ZHAO ${ }^{1}$, TAO WANG ${ }^{2}$, QIMING LV ${ }^{2}$ and NAN ZHOU ${ }^{3}$ \\ ${ }^{1}$ Department of Neurosurgery, Binzhou Center Hospital, Binzhou, Shandong 251700; ${ }^{2}$ Department of Neurosurgery, \\ Liaocheng Third People's Hospital, Liaocheng, Shandong 252000; ${ }^{3}$ Department of Health Care, \\ Jinan Central Hospital, Jinan, Shandong 250013, P.R. China
}

Received May 13, 2019; Accepted October 24, 2019

DOI: $10.3892 /$ etm.2019.8357

\begin{abstract}
Trends of early expression levels of heat shock protein 70 (Hsp70) and Annexin A1 (ANXA1) in serum of patients with acutely severe traumatic brain injury and the effects on clinical prognosis were investigated. Eighty-four patients with severe traumatic brain injury admitted to Binzhou Center Hospital from June 2014 to July 2017 were selected as the experimental group. Glasgow coma scale and acute physiology and chronic health evaluation II (APACHE II) score were obtained after admission. A further 75 healthy subjects were selected as the control group. Serum expression of Hsp70 and ANXA1 in the two groups was detected by enzyme-linked immunosorbent assay on the 1st, 2nd, 3rd and 4th day after admission. The receiver operating characteristic (ROC) curve was used to analyze the diagnostic value of Hsp70 and ANXA1 for the death of patients with acutely severe traumatic brain injury. Compared with the control group, expression of Hsp70 in the experimental group was significantly increased on the 1st, 2nd, 3rd and 4th day after admission $(\mathrm{P}<0.05)$, while expression of ANXA1 was significantly decreased $(\mathrm{P}<0.05)$. Expression levels of serum Hsp70 in the experimental group reached the peak on the 3rd day after admission, and the difference was statistically significant compared with the 1st, 2nd and 4th day $(\mathrm{P}<0.05)$. Expression of ANXA1 was the lowest on the 3rd day, and the difference was statistically significant compared with the 1 st, 2 nd and 4 th day $(\mathrm{P}<0.05)$. The ROC curve analysis showed that the area under the curve of serum Hsp70 and ANXA1 was, respectively, $0.721(95 \%$ CI: 0.611-0.829) and 0.684 (95\% CI: 0.569-0.799). In conclusion, Hsp70 and ANXA1 may be involved in the occurrence and progression of acutely severe traumatic brain injury. The
\end{abstract}

Correspondence to: Dr Nan Zhou, Department of Health Care, Jinan Central Hospital, 105 Jiefang Road, Jinan, Shandong 250013, P.R. China

E-mail: zrjh99@163.com

Key words: severe traumatic brain injury, heat shock protein 70 , Annexin A1, diagnostic value detection of serum Hsp70 and ANXA1 has certain diagnostic value for the death of patients with acutely severe traumatic brain injury.

\section{Introduction}

Traumatic brain injury is a trauma with high disability and mortality. About $22 \%$ of the patients with severe brain injury are severely disabled, $5 \%$ are in vegetative state and $40 \%$ die $(1,2)$. An acutely severe brain injury is caused by violent impact on the head, resulting in brain contusion, brain edema, disturbance of consciousness and other symptoms. Most patients are critically ill, and their conditions change rapidly; the morbidity and mortality are quite high (3). There are currently no drugs available for effective treatment. With the increase of accidents such as car accidents and falling objects, the number of patients with acutely severe brain injury is on the rise (4).

Heat shock protein 70 (Hsp70) is a stress protein that maintains its own stability (5). In recent years, a large number of studies have confirmed that Hsp70 is rapidly induced in the brain damage of mammals, and has obvious protective effects on the body and brain $(6,7)$. In previous findings, immunohistochemical staining was used to directly detect the expression of Hsp70 in brain tissue, and the subjects were limited to experimental animal models $(8,9)$. Annexin A1 (ANXA1), a calcium-dependent phospholipid-binding protein, is a member of the annexin family (10). ANXA1 has been shown to be involved in the regulation of important endogenous factors in the blood-brain barrier of patients with multiple sclerosis (11). ANXA1 on either side of the cell membrane and ANXA1 out of cells interact with actin to form FPR2 receptor as well as cytoskeleton interactions to shape stable tight junctions between the cells, which is of great significance for maintaining the integrity of the blood-brain barrier (12). However, the relationship between ANXA1 and acutely severe traumatic brain injury remains to be elucidated.

The purpose of this study was to provide a feasible method for early assessment of patients with acutely severe traumatic brain injury by observing the changes of expression levels of serum Hsp70 and ANXA1, and studying the diagnostic values of Hsp70 and ANXA1 in the diagnosis of acute severe traumatic brain injury. 


\section{Patients and methods}

Patients. Eighty-four patients with severe traumatic brain injury were admitted to Binzhou Center Hospital (Binzhou) from June 2014 to July 2017. These patients with severe traumatic brain injury were the experimental group, including 49 males and 35 females, aged from 16 to 70 years, and with the mean age of $41.24 \pm 6.56$ years. A further 75 healthy subjects in the same period were the control group, including 47 males and 28 females; aged from 18 to 70 years, and with the mean age of $43.68 \pm 7.53$ years. The mean acute physiology and chronic health evaluation II (APACHE II) score (13) was 28.27 \pm 5.21 points. The mean Glasgow Coma Scale (GCS) score for the severe traumatic brain injury was $6.12 \pm 1.17$ points. The inclusion criteria were: The time from trauma to admission of patients in the experimental group was $<6 \mathrm{~h}$; severe traumatic brain injury (GCS score $\leq 8)(14)$, and brain contusion, subarachnoid hemorrhage, cerebral hemorrhage, epidural hematoma, subdural hematoma, diffuse brain swelling, skull base fracture and cranial bone fracture were confirmed by head CT, and the patients were admitted to hospital within $6 \mathrm{~h}$ after injury. The healthy control group was examined in the physical examination center of the hospital and the results were normal; patients had no other type of tumor, heart, liver, kidney or other important organ diseases and no family members with a history of cancer.

The study was reviewed and approved by the ethics committee of Binzhou Center Hospital, and all the patients or their guardians signed an informed consent form. The exclusion criteria were: Patients with combined injury; with hypoxemia after trauma; with previous severe organic disease such as hypotension as well as liver and kidney dysfunction; with neurodegenerative diseases, depression, other nervous system diseases, autoimmune diseases and severe metabolic disorders. Patients in the experimental group were given routine treatment after admission, including maintaining airway patency, dehydration, hemostasis, anti-infection, acid production, nutritional cranial nerves, support and symptomatic treatment. After admission, blood was taken on the 1 st day and centrifuged, and the supernatant was taken for use. When the patient was discharged from hospital, they were divided according to the Glasgow Outcome Scale (GOS). Good recovery: returning to normal life with mild defects; mild disability: disabled but living independently, able to work under protection; severe disability: awake, disability, need care in daily life; vegetative state: only minimal response (e.g., the eyes could open with the sleep/wake cycle); or dead.

Main instruments and reagents. Hsp70 enzyme-linked immunoassay kit (Biorbyt, UK, orb55612); ANXA1 enzyme-linked immunoassay kit (Biorbyt, UK, orb437946); enzyme-linked immunoassay meter (Molecular Devices, US, Spectra MaxiD5).

Methods of detection. The expression levels of serum Hsp70 and ANXA1 were detected by enzyme-linked immunosorbent assay (ELISA): The required slats were taken out from the aluminum foil bag which was equilibrated for $20 \mathrm{~min}$ at room temperature, and the remaining slats were sealed with a ziplock bag and returned to the refrigerator at $4^{\circ} \mathrm{C}$. Standard and sample wells were set, and $50 \mu \mathrm{l}$ standard with different expression was added to the standard wells; $50 \mu$ l of the sample to be tested was added into the sample well; the blank wells were not added; $100 \mu \mathrm{l}$ of detection antibody labeled by horseradish peroxidase was added to each standard well and sample well, and reaction wells were sealed with a sealing membrane, and then incubated at $37^{\circ} \mathrm{C}$ in an incubator for $60 \mathrm{~min}$; the liquid was discarded, and then the wells were patted dry with absorbent paper, filled with the washing solution $(350 \mu \mathrm{l})$, and left to stand for $1 \mathrm{~min}$. The washing solution was removed, patted dry with absorbent paper, and the plate washing was repeated 5 times; $50 \mu \mathrm{l}$ of substrate A and $50 \mu \mathrm{l}$ of substrate B were added to each well, incubated at $37^{\circ} \mathrm{C}$ for $15 \mathrm{~min}$ in the dark; $50 \mu \mathrm{l}$ of the stopping solution was added to each well, and the OD value of each well was measured at a wavelength of $450 \mathrm{~nm}$ of the enzyme-linked immunosorbent meter within $15 \mathrm{~min}$.

Statistical analysis. Data were statistically analyzed by SPSS 22.0 statistical analysis software (IBM Corp, Armonk, NY, USA). The enumeration data were expressed by number of cases/percentage [n (\%)], and the comparison of enumeration data between groups was tested by the Chi-square test. The measurement data were expressed as mean \pm standard deviation (mean $\pm \mathrm{SD}$ ), and the comparison of measurement data between groups was performed by an independent sample t-test. One-way analysis of variance (ANOVA) was used for the comparison between multiple groups of means, and the Tukey test was used for subsequent pairwise comparisons. Comparison between multiple time points was performed by repeated measures analysis of variance, and the subsequent pairwise comparison was performed by the Bonferroni test. The receiver operating characteristic (ROC) curve was used to evaluate the efficacy of Hsp70 and ANXA1 in diagnosing death from acutely severe traumatic brain injury. $\mathrm{P}<0.05$ was considered as statistically significant.

\section{Results}

Two sets of patients. There were no significant differences in the general data regarding sex, age, history of smoking and drinking between the control and experimental groups $(\mathrm{P}>0.05)$ (Table I).

Expression levels of serum Hsp70 and ANXAl in the experimental group at different time points of admission compared to the control group. Compared with the control group, the expression of Hsp70 in the experimental group was significantly increased on the 1st, 2 nd, 3rd and 4th day after admission $(\mathrm{P}<0.05)$, while expression of ANXA1 was significantly decreased $(\mathrm{P}<0.05)$. The expression level of serum Hsp70 in the experimental group peaked on the 3rd day after admission, and differences were statistically significant compared with that on the 1 st, 2 nd and 4 th day $(\mathrm{P}<0.05)$. The expression of ANXA1 was the lowest on the 3rd day, and differences were statistically significant compared with that on the 1st, 2nd, and 4th day $(\mathrm{P}<0.05)$ (Table II and Fig. 1).

Expression levels of serum Hsp70 and ANXAl in groups relating to survival. A total of 47 patients survived (survival group) and 37 patients died (death group) in the 
Table I. Patient data [n (\%), mean \pm SD]

\begin{tabular}{|c|c|c|c|c|}
\hline Classification & $\begin{array}{c}\text { Control } \\
\text { group }(n=75)\end{array}$ & $\begin{array}{l}\text { Experimental } \\
\text { group }(n=84)\end{array}$ & $\chi^{2 / t}$ & P-value \\
\hline Sex & & & 0.311 & 0.577 \\
\hline Male & $47(62.67)$ & $49(58.33)$ & & \\
\hline Female & $28(37.33)$ & $35(41.67)$ & & \\
\hline Age (years) & $43.68 \pm 7.53$ & $41.24 \pm 6.56$ & 0.499 & 0.667 \\
\hline History of smoking & & & 0.161 & 0.688 \\
\hline Yes & $36(48.00)$ & $43(51.19)$ & & \\
\hline No & $39(52.00)$ & $41(48.81)$ & & \\
\hline History of drinking & & & 0.288 & 0.592 \\
\hline Yes & $46(61.33)$ & $48(57.14)$ & & \\
\hline No & $29(38.67)$ & $36(42.86)$ & & \\
\hline BMI $\left(\mathrm{kg} / \mathrm{m}^{2}\right)$ & $21.15 \pm 2.31$ & $21.54 \pm 2.73$ & 0.499 & 0.667 \\
\hline Place of residence & & & 0.392 & 0.531 \\
\hline Country & $43(57.33)$ & $44(52.38)$ & & \\
\hline City & $32(42.67)$ & $40(47.62)$ & & \\
\hline Marital status & & & 0.039 & 0.843 \\
\hline Single & $36(48.00)$ & $39(46.43)$ & & \\
\hline Married & $39(52.00)$ & $45(53.57)$ & & \\
\hline Cultural degree & & & 1.661 & 0.198 \\
\hline A high school education or less & $37(49.33)$ & $50(59.52)$ & & \\
\hline Above senior high school education & $38(50.67)$ & $34(40.48)$ & & \\
\hline Working condition & & & 0.266 & 0.606 \\
\hline No & $30(40.00)$ & $37(44.05)$ & & \\
\hline Yes & $45(60.00)$ & $47(55.95)$ & & \\
\hline AST (U/l) & $19.23 \pm 7.08$ & $18.19 \pm 7.13$ & 0.921 & 0.358 \\
\hline ALT (U/l) & $22.25 \pm 9.37$ & $21.76 \pm 10.21$ & 0.314 & 0.754 \\
\hline
\end{tabular}

BMI, body mass index; AST, aspartate aminotransferase; ALT, alanine aminotransferase; SD, standard deviation.

Table II. Comparison of levels of serum Hsp70 and ANXA1 between the two groups (mean \pm SD).

\begin{tabular}{|c|c|c|c|c|}
\hline Groups & $\mathrm{n}$ & $\begin{array}{c}\text { Time after } \\
\text { admission (days) }\end{array}$ & $\begin{array}{l}\text { Hsp70 } \\
(\mathrm{ng} / \mathrm{ml})\end{array}$ & $\begin{array}{l}\text { ANXA1 } \\
(\mathrm{ng} / \mathrm{ml})\end{array}$ \\
\hline Control & 75 & - & $2.261 \pm 0.188$ & $2.095 \pm 0.321$ \\
\hline \multirow[t]{4}{*}{ Experimental } & 84 & 1 & $4.177 \pm 1.623^{\mathrm{a}}$ & $1.137 \pm 0.158^{\mathrm{a}}$ \\
\hline & & 2 & $8.497 \pm 3.206^{\mathrm{a}, \mathrm{b}}$ & $0.736 \pm 0.351^{\mathrm{a}, \mathrm{b}}$ \\
\hline & & 3 & $9.194 \pm 3.614^{\mathrm{a}-\mathrm{c}}$ & $0.553 \pm 0.236^{\mathrm{a}-\mathrm{c}}$ \\
\hline & & 4 & $6.822 \pm 3.642^{\mathrm{a}-\mathrm{d}}$ & $0.852 \pm 0.243^{\mathrm{a}-\mathrm{d}}$ \\
\hline F-value & - & - & 42.64 & 76.62 \\
\hline P-value & - & - & $<0.001$ & $<0.001$ \\
\hline
\end{tabular}

${ }^{\mathrm{a}} \mathrm{P}<0.05$, compared with the control group; ${ }^{\mathrm{b}} \mathrm{P}<0.05$, compared with one day after admission; ${ }^{\mathrm{c}} \mathrm{P}<0.05$, compared with two days after admission; ${ }^{\mathrm{d}} \mathrm{P}<0.05$, compared with three days after admission. Hsp70, heat shock protein 70; ANXA1, Annexin A1; SD, standard deviation.

experimental group during the treatment. The serum Hsp70 in the survival group was significantly lower than that in the death group on the 1 st day after admission $(\mathrm{P}<0.001)$, while the expression level of ANXA1 was significantly higher than that in the death group $(\mathrm{P}<0.001)$ (Table III and Fig. 2). 

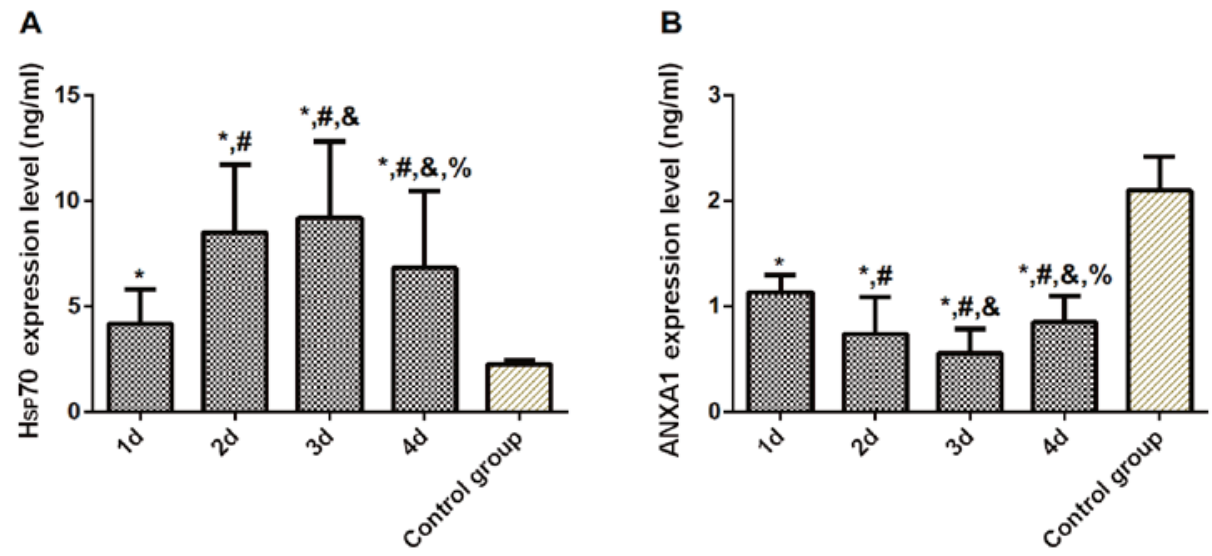

Figure 1. Comparison of expression levels of serum Hsp70 and ANXA1 in the experimental group at different time points of admission and in the control group. (A) The results of expression of serum ANXA1 in the experimental group at different time points of admission and in the control group were compared. (B) The results of expression of serum Hsp70 in the experimental group at different time points of admission and in the control group were compared. "P<0.05, compared with the control group; ${ }^{\prime \prime} \mathrm{P}<0.05$, compared with one day after admission; ${ }^{\&} \mathrm{P}<0.05$, compared with two days after admission; ${ }^{\%} \mathrm{P}<0.05$, compared with three days after admission. Hsp70, heat shock protein 70; ANXA1, Annexin A1.

A

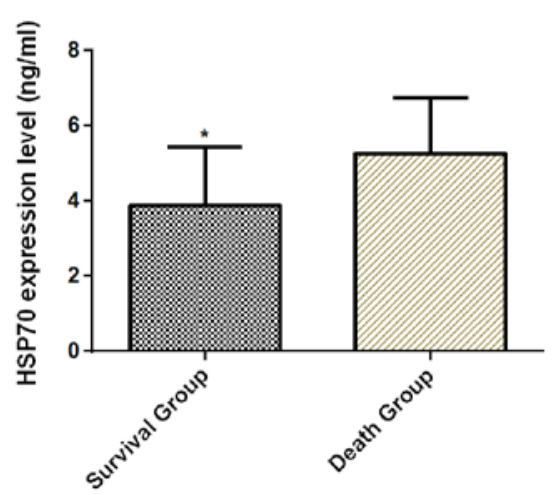

B

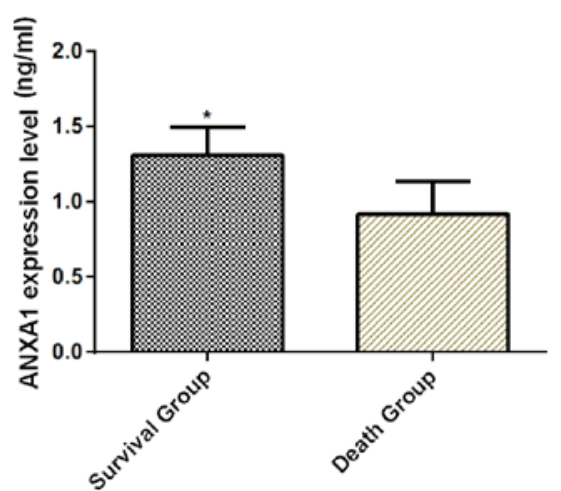

Figure 2. Comparison of results of expression levels of serum Hsp70 and ANXA1 in the groups of survival and death. (A) Comparison of results of expression levels of serum Hsp70 in the survival and death group. (B) Comparison of results of expression levels of serum ANXA1 in the survival and death group."P<0.05, compared with death group. Hsp70, heat shock protein 70; ANXA1, Annexin A1.

Diagnostic value of Hsp70 and ANXA1 in the diagnosis of acutely severe traumatic brain injury. The ROC curves of expression of serum Hsp70 and ANXA1 in the diagnosis of acutely severe traumatic brain injury were drawn. The area under the curve (AUC) of serum Hsp70 in the diagnosis of death of patients with acutely severe traumatic brain injury was 0.721 (95\% CI: 0.611-0.829), and the cut-off value was $4.235 \mathrm{ng} / \mathrm{ml}$; the diagnostic sensitivity was $83.78 \%$, and the specificity was $57.45 \%$. The AUC of serum ANXA1 in the diagnosis of death of patients with acutely severe traumatic brain injury was 0.684 (95\% CI: 0.569-0.799), and the cut-off value was $1.163 \mathrm{ng} / \mathrm{ml}$; the diagnostic sensitivity was $64.86 \%$, and the specificity was $63.83 \%$ (Table IV and Fig. 3).

Relationship between relative expression levels of $H s p 70$ and ANXAl in APACHE II score. Serum Hsp70 and ANXA1 expression was significantly different in patients with different APACHE II scores $(\mathrm{P}<0.05)$. Compared with the APACHE II score $<10$ points, the serum Hsp70 expression level of patients with APACHE II scores of 11-20, $20-30$, and $>30$ was significantly increased $(P<0.05)$, and the serum ANXA1 expression level was significantly decreased
Table III. Comparison of results of expression levels of serum Hsp70 and ANXA1 between the survival and the death group on the 1st day after admission (mean $\pm \mathrm{SD}$ ).

\begin{tabular}{lccc}
\hline Groups & $\mathrm{n}$ & $\begin{array}{c}\text { Hsp70 } \\
(\mathrm{ng} / \mathrm{ml})\end{array}$ & $\begin{array}{c}\text { ANXA1 } \\
(\mathrm{ng} / \mathrm{ml})\end{array}$ \\
\hline Survival & 47 & $3.884 \pm 1.545$ & $1.309 \pm 0.187$ \\
Death & 37 & $5.264 \pm 1.476$ & $0.919 \pm 0.217$ \\
t-value & & 4.280 & 4.247 \\
P-value & & $<0.001$ & $<0.001$ \\
\hline
\end{tabular}

Hsp70, heat shock protein 70; ANXA1, Annexin A1; SD, standard deviation.

$(\mathrm{P}<0.05)$. Compared with the group of APACHE II score of 11-20 points, the serum ANXA1 level of APACHE II score 21-30 group was significantly lower than that of APACHE II score 11-20 group $(\mathrm{P}<0.05)$, while Hsp70 was not significantly different between the two groups $(P>0.05)$. The expression 
Table IV. Diagnostic value of serum Hsp70 and ANXA1 for death in acutely severe traumatic brain injury.

\begin{tabular}{lcccccc}
\hline Diagnosis index & AUC & $95 \%$ CI & Standard error & Cut-off value & Sensitivity $(\%)$ & Specificity (\%) \\
\hline Hsp70 & 0.721 & $0.611-0.829$ & 0.056 & $4.235(\mathrm{ng} / \mathrm{ml})$ & 83.78 & 57.45 \\
ANXA1 & 0.684 & $0.569-0.799$ & 0.059 & $1.163(\mathrm{ng} / \mathrm{ml})$ & 64.86 & 63.83 \\
\hline
\end{tabular}

Hsp70, heat shock protein 70; ANXA1, Annexin A1; AUC, area under the curve; CI, confidence index.

Table V. Relationship between the relative expression levels of serum Hsp70 and ANXA1 and the APACHE II score in patients with acute severe traumatic brain injury (mean $\pm \mathrm{SD}$ ).

\begin{tabular}{lrcc}
\hline $\begin{array}{l}\text { APACHE II } \\
\text { score (points) }\end{array}$ & $\mathrm{n}$ & $\begin{array}{c}\text { Hsp70 } \\
(\mathrm{ng} / \mathrm{ml})\end{array}$ & $\begin{array}{c}\text { ANXA1 } \\
(\mathrm{ng} / \mathrm{ml})\end{array}$ \\
\hline$<10$ & 4 & $2.49 \pm 1.17$ & $1.865 \pm 0.233$ \\
$11-20$ & 28 & $5.67 \pm 2.32^{\mathrm{a}}$ & $1.326 \pm 0.419^{\mathrm{a}}$ \\
$21-30$ & 31 & $6.68 \pm 2.98^{\mathrm{a}}$ & $1.027 \pm 0.259^{\mathrm{a}, \mathrm{b}}$ \\
$>30$ & 21 & $8.55 \pm 3.63^{\mathrm{a}-\mathrm{c}}$ & $0.556 \pm 0.184^{\mathrm{a}-\mathrm{c}}$ \\
F-value & & 6.744 & 34.880 \\
P-value & & $<0.001$ & $<0.001$ \\
\hline
\end{tabular}

${ }^{\mathrm{a}} \mathrm{P}<0.05$, compared with APACHE II score $<10$ points; ${ }^{\mathrm{b}} \mathrm{P}<0.05$ compared with APACHE II score 11-20 points; ${ }^{\mathrm{C}} \mathrm{P}<0.05$, compared to APACHE II score 21-30 points. Hsp70, heat shock protein 70; ANXA1, Annexin A1; APACHE II, acute physiology and chronic health evaluation II.

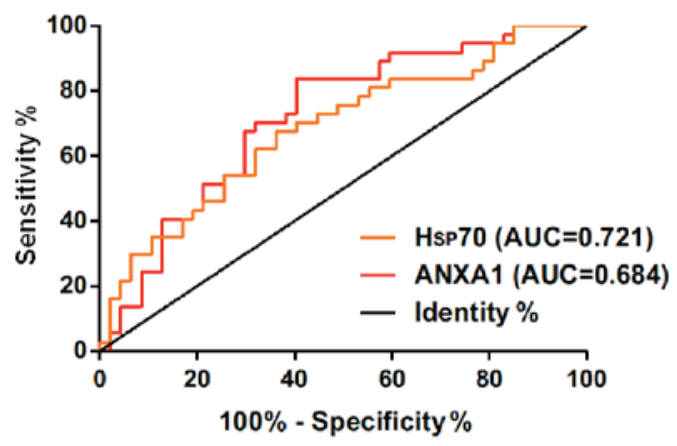

Figure 3. ROC curves of expression levels of serum Hsp70 and ANXA1 in the diagnosis of death in patients with acutely severe traumatic brain injury. Hsp70, heat shock protein; ANXA1, Annexin A1.

level of serum Hsp70 in APACHE II score $>30$ group was significantly higher than other groups $(\mathrm{P}<0.05)$, and the serum ANXA1 expression level was significantly lower than the other groups $(\mathrm{P}<0.05)($ Table $\mathrm{V})$.

Relationship between the relative expression levels of Hsp70 and ANXA1 and the GOS score. Hsp70 and ANXA1 expression of serum was significantly different in patients with different GOS assessment results $(\mathrm{P}<0.05)$. Compared to patients with good recovery, serum Hsp70 expression levels were significantly increased in patients with mild disability, in vegetative state, and the dead $(\mathrm{P}<0.05)$; serum
Table VI. GOS scores.

\begin{tabular}{llcc}
\hline $\begin{array}{l}\text { GOS assessment } \\
\text { results }\end{array}$ & $\mathrm{n}$ & $\begin{array}{c}\text { Hsp70 } \\
(\mathrm{ng} / \mathrm{ml})\end{array}$ & $\begin{array}{c}\text { ANXA1 } \\
(\mathrm{ng} / \mathrm{ml})\end{array}$ \\
\hline Good recovery & 7 & $1.942 \pm 0.852$ & $1.873 \pm 0.199$ \\
Mild disability & 23 & $3.398 \pm 1.459^{\mathrm{a}}$ & $1.405 \pm 0.324^{\mathrm{a}}$ \\
Vegetative state & 17 & $4.571 \pm 2.372^{\mathrm{a}}$ & $1.029 \pm 0.305^{\mathrm{a}, \mathrm{b}}$ \\
Death & 37 & $5.264 \pm 1.476^{\mathrm{a}, \mathrm{b}}$ & $0.919 \pm 0.217^{\mathrm{a}, \mathrm{b}}$ \\
F-value & & 11.36 & 34.33 \\
P-value & & $<0.001$ & $<0.001$ \\
\hline
\end{tabular}

${ }^{\mathrm{a}} \mathrm{P}<0.05$, compared with good recovery; ${ }^{\mathrm{b}} \mathrm{P}<0.05$, compared with mild disability. GOS, Glasgow Outcome Scale; Hsp70, heat shock protein 70; ANXA1, Annexin A1.

ANXA1 expression levels were significantly decreased $(\mathrm{P}<0.05)$. Compared to patients with mild disability, the serum ANXA1 levels in the patients in vegetative state and the dead were significantly lower $(\mathrm{P}<0.05)$, while the serum Hsp70 and ANXA1 expression levels were not significantly different between the patients in vegetative state and the dead $(\mathrm{P}>0.05)$ (Table VI).

\section{Discussion}

Patients with acutely severe traumatic brain injury have obvious oxidative stress and inflammatory response. Excessive activation of inflammatory response leads to increased cerebral vascular permeability, increased leukocyte release, and complement activation, resulting in a cascade of inflammatory factors and aggravating secondary damage of brain tissue (15). The support and functional testing of all organ systems is a way to improve the success rate of severe traumatic brain injury and reduce the death of clinical patients $(16,17)$.

Previous studies have shown that Hsp70 expression was increased in the process of injury tissue cells and has protective effects on cells (18-20). Zhang et al (21) found that Hsp70 signaling pathway can regulate TLR4-Trif-Stat3 signaling, thereby inhibiting NOX3 induction and reducing oxidative damage in the lung. Xia et al (22) found that Hsp70 can prevent brain ischemia-reperfusion injury and protect the nerve. Ren et al (23) found that expression level of serum Hsp70 can reflect the extent of cell damage by detecting the expression of Hsp70 in three time periods after trauma, and that expression level of serum Hsp70 was significantly higher in patients with mild, moderate, and severe injury than in healthy patients, and expression levels of serum Hsp70 in the severely injured 
group were significantly higher than those in the lightly injured group in 1 to $6 \mathrm{~h}$ after trauma. However, we observed that expression level of serum Hsp70 in experimental group reached the peak 3 days after admission, which was statistically significant compared with that on the 1st, 2nd, and 4th day, and greatly higher than those of the control group. We speculate that the change of Hsp70 level reflects the degree of craniocerebral injury to some extent. The damaged brain tissue has strong stress and anti-injury ability within 3 days, so it can secrete inflammatory factors and promote the body to produce a large amount of Hsp70 for anti-injury and repair. The increased expression may be beneficial to the repair of nerve cell damage. da Rocha et al (24) measured Hsp70 levels in 20 male patients with traumatic brain injury at the time of admission, $24 \mathrm{~h}$ and 7 days after admission. Compared with the control group, serum Hsp70 concentration was significantly increased in patients with severe traumatic brain injury. The serum Hsp70 concentration reached the peak at the time of admission, but they did not measure the concentration on the 3rd and 5th day of admission and the concentrations of female patients. Therefore, there is difference in the peak time of Hsp in their study and ours, which may be caused by the difference in measurement time and subjects. This is similar to studies of Ren et al (23). ANXA1 regulates the function of the bloodbrain barrier, which plays an important role in regulating the integrity of the blood-brain barrier by promoting the restoration of polarity of cerebrovascular skin cells and cytoskeletal integrity. Capraz et al (25) found that ANXA1 disappeared in the cerebrovascular and ependymal hypoxia injury within $24 \mathrm{~h}$ and induced up-regulation after injury of microglial cells in $72 \mathrm{~h}$, showing that extracellular vesicles with ANXA1 can alleviate the damage of blood-brain barrier caused by ischemia and hypoxia. Sen et al (26) showed that ANXA1 may regulate blood-brain barrier function by promoting the recovery of cerebrovascular skin cells. Luo et al (27) found that ANXA1 can also exert neuroprotective effects on brain damage by polarizing microglia cells into beneficial phenotypes. The results of the present study showed that the expression of serum ANXA1 in the experimental group was the lowest on the 3rd day, which was statistically significant compared with that on the 1st, 2nd and 4th day, and significantly higher than that of the control group. Wang et al (28) found that the expression of ANXA1 decreased after cerebral hemorrhage, and the increase of the expression of ANXA1 can improve conditions of necrosis in cerebrovascular skin cells and neurons, and reduce brain edema after cerebral hemorrhage, which was similar to our study. Our study found that patients with different APACHE II scores and GOS assessment results had different levels of Hsp70 and ANXA1 expression. Hsp70 and ANXA1 may be involved in the development of patients with acutely severe traumatic brain injury, which may be related to poor prognosis. Therefore, we further evaluated the ROC curve of poor prognosis in patients with acutely severe traumatic brain injury by serum Hsp70 and ANXA1 on the first day after admission, and the results showed that serum Hsp70 and ANXA1 have certain value in the diagnosis of death in patients with acutely severe traumatic brain injury. Detecting the expression levels of Hsp70 and ANXA1 in the serum of patients with acutely severe traumatic brain injury has certain predictive value for the diagnosis of death of patients.
In summary, Hsp70 and ANXA1 may be involved in the occurrence and progression of acutely severe traumatic brain injury. The detection of serum Hsp70 and ANXA1 has certain diagnostic value for the death of patients with acutely severe traumatic brain injury.

\section{Acknowledgements}

Not applicable.

\section{Funding}

No funding was received.

\section{Availability of data and materials}

The datasets used and/or analyzed during the present study are available from the corresponding author on reasonable request.

\section{Authors' contributions}

JZ and TW analyzed and interpreted the patient general data. QL performed ELISA. NZ was responsible for the analysis of the observation indicators. JZ wrote the manuscript. All authors read and approved the final manuscript.

\section{Ethics approval and consent to participate}

The study was approved by the Ethics Committee of Binzhou Center Hospital (Binzhou). Patients who participated in this research, signed an informed consent and had complete clinical data. Signed informed consents were obtained from the patients or the guardians.

\section{Patient consent for publication}

Not applicable.

\section{Competing interests}

The authors declare that they have no competing interests.

\section{References}

1. Sun Z, Zuo H, Yuan D, Sun Y, Zhang K, Cui Z and Wang J: Predictors of prognosis in patients with temporal lobe epilepsy after anterior temporal lobectomy. Exp Ther Med 10: 1896-1902, 2015.

2. Memarian N, Kim S, Dewar S, Engel J Jr and Staba RJ: Multimodal data and machine learning for surgery outcome prediction in complicated cases of mesial temporal lobe epilepsy. Comput Biol Med 64: 67-78, 2015.

3. Chen F, Xu C and Zhang C: Effect of indwelling nasointestinal tube for enteral nutrition support in patients with severe craniocerebral trauma undergoing mechanical ventilation. Zhonghua Wei Zhong Bing Ji Jiu Yi Xue 30: 57-60, 2018 (In Chinese).

4. Xu G, Hu B, Chen G, Yu X, Luo J, Lv J and Gu J: Analysis of blood trace elements and biochemical indexes levels in severe craniocerebral trauma adults with Glasgow Coma Scale and injury severity score. Biol Trace Elem Res 164: 192-197, 2015.

5. Benjamin IJ and McMillan DR: Stress (heat shock) proteins: Molecular chaperones in cardiovascular biology and disease. Circ Res 83: 117-132, 1998. 
6. Wang T, Yu DR, Huang J, Liu Q, Wang DX, Luo N, Jia H, Fan HF and Liu QB: Multimodal rehabilitation program promotes motor function recovery of rats after ischemic stroke by upregulating expressions of GAP-43, SYN, HSP70, and C-MYC. J Stroke Cerebrovasc Dis 27: 2829-2839, 2018

7. Yurinskaya MM, Funikov SY, Evgen'ev MB and Vinokurov MG: Exogenous heat shock protein HSP70 reduces response of human neuroblastoma cells to lipopolysaccharide. Dokl Biochem Biophys 469: 239-243, 2016.

8. Cheng CY, Kao ST and Lee YC: Ferulic acid exerts anti-apoptotic effects against ischemic injury by activating HSP70/Bcl-2- and HSP70/autophagy-mediated signaling after permanent focal cerebral ischemia in rats. Am J Chin Med 47: 39-61, 2019.

9. Zhou Y, Niu LJ, Qi FM and Guo L: Effect of 3-n-butylphthalide pretreatment on expression of the HSP70 after brain ischemia/ reperfusion. Zhongguo Ying Yong Sheng Li Xue Za Zhi 31: 136-140, 2015 (In Chinese).

10. Grewal T, Wason SJ, Enrich C and Rentero C: Annexins - insights from knockout mice. Biol Chem 397: 1031-1053, 2016.

11. Cristante E, McArthur S, Mauro C, Maggioli E, Romero IA Wylezinska-Arridge M, Couraud PO, Lopez-Tremoleda J, Christian HC, Weksler BB, et al: Identification of an essential endogenous regulator of blood-brain barrier integrity, and its pathological and therapeutic implications. Proc Natl Acad Sci USA 110: 832-841, 2013 .

12. Xiong $\mathrm{J}$ and Feng Y: Effect of dl-3-N-butylphthalide on the expression of hsp70 mRNA and c-fos in transient cerebral ischemic and reperfused rat brain. Yao Xue Xue Bao 33: 401-406, 1998 (In Chinese).

13. Brennan PM, Murray GD and Teasdale GM: Simplifying the use of prognostic information in traumatic brain injury. Part 1: The GCS-Pupils score: An extended index of clinical severity. J Neurosurg 128: 1612-1620, 2018

14. Godinjak A, Iglica A, Rama A, Tančica I, Jusufović S, Ajanović A and Kukuljac A: Predictive value of SAPS II and APACHE II scoring systems for patient outcome in a medical intensive care unit. Acta Med Acad 45: 97-103, 2016.

15. Ziebell JM and Morganti-Kossmann MC: Involvement of pro- and anti-inflammatory cytokines and chemokines in the pathophysiology of traumatic brain injury. Neurotherapeutics 7: $22-30,2010$

16. Kim J, Kim SH, Lim SC, Kim W and Shon YM: Clinical characteristics of patients with benign nonlesional temporal lobe epilepsy. Neuropsychiatr Dis Treat 12: 1887-1891, 2016.

17. Deane CAS and Brown IR: Knockdown of heat shock proteins HSPA6 (Hsp70B') and HSPA1A (Hsp70-1) sensitizes differentiated human neuronal cells to cellular stress. Neurochem Res 43 340-350, 2018.

18. Yan J, Liang X, Zhang Y, Li Y, Cao X and Gao J: Cloning of three heat shock protein genes (HSP70, HSP90 $\alpha$ and HSP90 $\beta$ ) and their expressions in response to thermal stress in loach (Misgurnus anguillicaudatus) fed with different levels of vitamin C. Fish Shellfish Immunol 66: 103-111, 2017.
19. Bidmon-Fliegenschnee B, Lederhuber HC, Csaicsich D, Pichler J, Herzog R, Memaran-Dadgar N, Huber WD, Aufricht C and Kratochwill K: Overexpression of Hsp70 confers cytoprotection during gliadin exposure in Caco-2 cells. Pediatr Res 78: 358-364, 2015.

20. Miova B, Dinevska-Kjovkarovska S, Esplugues JV and Apostolova N: Heat stress induces extended plateau of Hsp70 accumulation - a possible cytoprotection mechanism in hepatic cells. J Cell Biochem 116: 2365-2374, 2015.

21. Zhang Y, Shan P, Srivastava A, Jiang G, Zhang X and Lee PJ: An endothelial Hsp70-TLR4 axis limits Nox3 expression and protects against oxidant injury in lungs. Antioxid Redox Signal 24: 991-1012, 2016.

22. Xia M, Ding Q, Zhang Z and Feng Q: Remote limb ischemic preconditioning protects rats against cerebral ischemia via HIF-1 $/$ /AMPK/HSP70 pathway. Cell Mol Neurobiol 37: 1105-1114, 2017.

23. Ren B, Zou G, Huang Y, Xu G, Xu F, He J, Zhu H and Yu P: Serum levels of HSP70 and other DAMP proteins can aid in patient diagnosis after traumatic injury. Cell Stress Chaperones 21: 677-686, 2016.

24. da Rocha AB, Zanoni C, de Freitas GR, André C, Himelfarb S, Schneider RF, Grivicich I, Borges L, Schwartsmann G, Kaufmann M and Regner A: Serum Hsp70 as an early predictor of fatal outcome after severe traumatic brain injury in males. J Neurotrauma 22: 966-977, 2005.

25. Capraz IY, Kurt G, Akdemir Ö, Hirfanoglu T, Oner Y, Sengezer T, Kapucu LO, Serdaroglu A and Bilir E: Annexin A1 as neuroprotective determinant for blood-brain barrier integrity in neonatal hypoxic-ischemic encephalopathy. Seizure 29: 63-68, 2015.

26. Sen A, Capelli V and Husain M: Cognition and dementia in older patients with epilepsy. Brain 141: 1592-1608, 2018.

27. Luo ZZ, Gao Y, Sun N, Zhao Y, Wang J, Tian B and Shi J: Enhancing the interaction between annexin-1 and formyl peptide receptors regulates microglial activation to protect neurons from ischemia-like injury. J Neuroimmunol 276: 24-36, 2014.

28. Wang Z, Chen Z, Yang J, Yang Z, Yin J, Zuo G, Duan X, Shen H, $\mathrm{Li} \mathrm{H}$ and Chen $\mathrm{G}$ : Identification of two phosphorylation sites essential for annexin A1 in blood-brain barrier protection after experimental intracerebral hemorrhage in rats. J Cereb Blood Flow Metab 37: 2509-2525, 2017.

This work is licensed under a Creative Commons Attribution-NonCommercial-NoDerivatives 4.0 International (CC BY-NC-ND 4.0) License. 